\title{
Comparison of Different Investment Decisions Linked with Discount Rate
}

\author{
Siting Zhang ${ }^{1, *}$ \\ ${ }^{1}$ Commence, Monash University, 3800, Melbourne, Australia \\ ${ }^{*}$ Corresponding author.Email: Szha0203@student.monash.edu
}

\begin{abstract}
Millions of companies make their investment decisions every minute in the world. They evaluate which projects can bring the most benefits or cost the least to them and then invest in these profitable projects. Hence, companies must have one or more practical and useful investment evaluation methods to help them achieve the ideal gains. Based on the situation, this article will discuss the existing evaluation methods such as IRR and NPV rules, payback methods, probability index and venture capitalists in the market. It will compare these methods and summary their own pros and cons to draw a clear picture of the investment criteria. Since this article find all the methods are not perfectly applied to investment, further research and studies of the most suitable investment evaluation methods will be looking forward to being finished.
\end{abstract}

Keywords: NPV, IRR, Payback method, Investment evaluation method, Company decision-making.

\section{INTRODUCTION}

Since every decision can bring future cash flows to the company and affect its value, even sometimes the consequences of the investment may not be positive and make a loss for the company. An investment decision method is a necessary tool for a company to evaluate its projects and make a correct investment decision to benefit itself. For example, Griffith and Liyanage [1] mention that Microsoft was bidding for a stake in Facebook in mid-2007. And it successfully bought the $1.6 \%$ stake with a $\$ 240$ million upfront cost. In addition, it also covered the costs of the development of the software platform and the network fundamental structure infrastructure and the international marketing. At the same time, it got the benefits of the increasing income associated with the advertising sales and the increasing value of the $1.5 \%$ stake in Facebook. In May 2012, Microsoft's shares were valued at over \$1 billion. Obviously, Microsoft has made an excellent investment strategy.

Since a company aims to maximize the wealth of the company's shareholders, and managers should make a profitable investment for shareholders, investment decision rules are critical in the decision-making process. There are many investment evaluation methods, and each of the methods has its own shortcomings and advantages. Therefore, this essay will discuss different evaluation methods and study their differences and characteristics.

NPV is a useful measure to help managers invest in projects. Hence, this article would discuss the NPV method. In addition, companies also use IRR and Payback methods. Companies always compare the return that shareholders can benefit from the investment in the capital market with the expected rate of return of equivalent risk projects. They will choose the projects that give them a higher return than shareholders can earn in the capital market. The different investments will be stated, and different methods will be used to solve the investment decision. All the evaluation methods will be compared, and the advantages and disadvantages of each method will be illustrated. Finally, the best investment project evaluation method will be provided.

Section 2 is to introduce different evaluation methods. The NPV, IRR rules, payback method, profitability index and venture capitalists will be described in detail, and some examples will be provided. For section 3, the comparison of these mentioned methods and discussion about the disadvantages and advantages of these evaluation methods will be given. For section 4 , the article will conclude the whole content and give the future research direction. 


\section{DIFFERENT EVALUATION METHOD}

In this section, the NPV, IRR, Payback, Profitability Index and VCs methods will be included, and each of them will be introduced in detail as follows.

\subsection{NPV method}

Berk and DeMarzo [2] explain that net present value is the difference between the present value of a project and its initial investment. Companies often accept projects with positive NPV and reject negative NPV to help shareholders earn profits.

Suppose there is a company A that invests in a project which costs $C_{0}$ at $t_{0}$ and it will bring $C_{1}$ in year 1 and $C_{2}$ in year 2 and $C_{3}$ in year 3 and so on. The risk-free rate is $r$. The NPV will be

$$
N P V=C_{0}+\frac{C_{1}}{1+r}+\frac{C_{3}}{(1+r)^{2}}+\frac{C_{4}}{(1+r)^{3}}+\cdots
$$

Brealey et al. [3] state that the NPV of the project is related to the cost of capital. However, the cost of capital is uncertain. In this case, an NPV profile which is a graph of NPV of the project based on the changed discount rate can be useful.

Suppose the relationship between NPV and the discount rate is shown below. Notice that the NPV is positive when the discount rate is less than $15 \%$, and the NPV is negative when the discount rate is greater than $15 \%$.

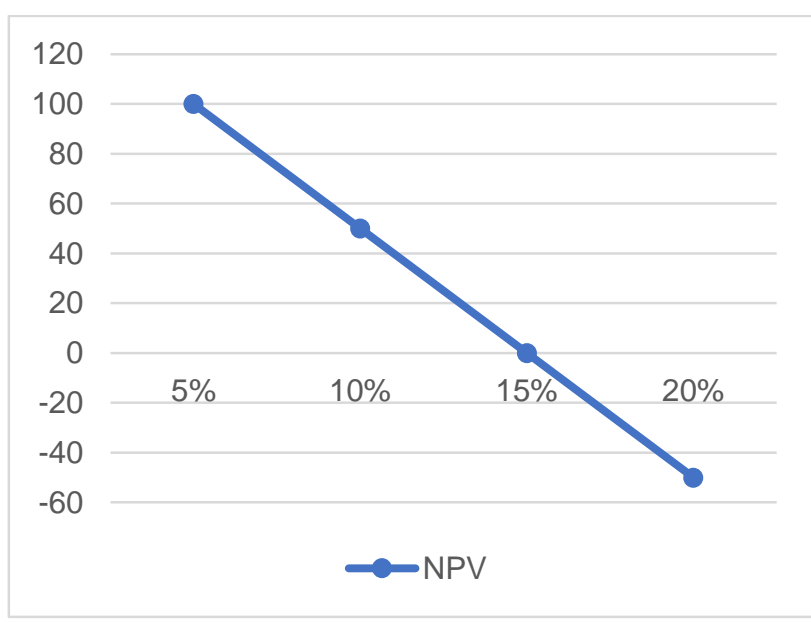

Figure 1. NPV of company A's project

Therefore, the investment project can be accepted when the discount rate is less than $15 \%$ and could be rejected when the discount rate is greater than $15 \%$

Allen and Myers [4] states that the NPV rule is the most reliable and accurate decision rule. However, they also point out that one-fourth of the American companies do not use the NPV method. They may use other rules, which can also give the same answer as the NPV rule.

\subsection{IRR method}

Internal rate of return has been recommended in many finance texts. Brealey et al. [3] interpret that the internal rate of return is the average return that the investment decision can produce if it is taken. The IRR rule is that if the internal rate of return on the investment decision is greater than the return on other alternatives with the same maturity and risk in the market, investors should accept the investment decision. If the opportunity where the IRR is less than the cost of capital, then the opportunity should be turned down.

Generally, the IRR rule will have the same conclusion as the NPV rule. However, it is not the case. In fact, Berk and DeMarzo [2] point out that the IRR rule only works for a stand-alone project, and the project has all negative cash flows before the positive cash flows. If it is not satisfied, the conclusion will be wrong, and the IRR rule will fall.

Suppose there is a famous painter, and he is paid 1 million upfront to paint. This procedure will take him three years ad each year will let him forgo other income accounting to 300,000 . Considering the opportunity cost of capital is $5 \%$.

The NPV of the decision is

$$
N P V=600,000-\frac{300,00}{1+r}-\frac{300,000}{(1+r)^{2}}-\frac{300,000}{(1+r)^{3}}
$$

Using the Excel function, the solution of $\mathrm{r}$ when NPV is set to be zero is $23.38 \%$

Table 1. IRR Excel calculation

\begin{tabular}{llllll}
\hline NPER & RATE & PV & PMT & FV & EXCEL FUNCTION \\
\hline 3 & & 600,000 & $-300,000$ & 0 & \\
& $23.38 \%$ & & & & $=$ RATE $(3,-300000,600000,0)$ \\
& & & & & \\
\hline
\end{tabular}

Since $5 \%<23.38 \%$, the opportunity cost of capital is largely less than IRR, the painter should accept the deal.

For NPV rule:

$$
N P V=600,000-\frac{300,00}{1+5 \%}-\frac{300,000}{(1+5 \%)^{2}}-\frac{300,000}{(1+5 \%)^{3}}=
$$$$
-761.624
$$

NPV is negative at a $5 \%$ discount rate., so the painter should reject the deal. Therefore, the IRR rule fails.

Tirole [5] states even if the IRR rule fails to work out the correct solution, the IRR rule still has its helped value by combing the NPV rule. It indicates the sensitivity of the investment decision in the cost of the capital estimate.

Now suppose that the dealer promises to give the painter a royalty payment when he finishes in exchange for a smaller initial payment. Specifically, he will receive 350,000 upfront payment and 600,000 when his 
paint is finished.

The NPV of the decision is

$$
\begin{aligned}
& N P V=350,000-\frac{300,00}{1+r}-\frac{300,000}{(1+r)^{2}}-\frac{300,000}{(1+r)^{3}}+ \\
& \frac{600,000}{(1+r)^{4}}
\end{aligned}
$$

For NPV rule:

$$
N P V=600,000-\frac{300,00}{1+5 \%}-\frac{300,000}{(1+5 \%)^{2}}-\frac{300,000}{(1+5 \%)^{3}}=
$$$$
-761.624
$$

Setting NPV equal to zero, the solution shows that there are two IRRs. Since there are two IRR, the IRR rule is not applied anymore.

Silber [6] mentions that when there is more than one IRR, the NPV rule is the best to evaluate.

In addition to multiple IRR, there is also a situation that IRR does not exist. That is, no discount rate can set NPV to zero. Hence, the IRR rule shows no guidance.

\subsection{Payback method}

Jaffe and Randolph Westerfield [7] provide another method that can act as a decision rule for standalone projects, which is the payback investment rule. It only accepts the project when all the discounted cash flows cover the initial investment within a certain period. It also explains the payback period. The payback period is the needed time to pay back the upfront investment. Suppose the payback period is less than the predetermined period, then it is advised to accept the project. On the other hand, if the payback period is larger than the predetermined period, it should not take the project.

Suppose that if a project has a payback period of four years. The projects require an initial payment of $\$ 300$ million and generate $\$ 55$ million per year. The sum of the cash flows for four years is $\$ 55^{*} 4=\$ 210$ million, which are less than the initial investment. The initial payment will be cover until year 6 since $\$ 55 * 6=$ $\$ 330$ million because the payback period is greater than five years. The project will be given up.

In reality, the payback method is not as a powerful tool as the NPV method. Berk and DeMarzo [2] sum up the reasons: firstly, the payback rule neglects the time value of money and the cost of capital. Secondly, it does not take the cash flows after the payback period into account. Thirdly, it depends on an ad hoc decision criterion. Although the payback rule has some shortcomings indeed, about $57 \%$ of firms use it in decision-making decisions. The reason behind that is its simplicity. It is time-consuming to compute NPV sometimes. However, If the required payback period is not long and the project satisfies the payback rule, the project will have a positive NPV, and the company can use the payback rule to save time. In addition, the payback rule is also useful for small investment decisions like purchasing a single machine, and it can provide budgeting information.

\subsection{Profitability Index}

Berk and DeMarzo [2] state profitability index is the ratio of the project's NPV to its initial investment. If multiple projects have positive NPV, the probability index is an efficient method to make the optimal combination.

Suppose there are three projects with a $\$ 100$ million budget. The project I will cost $\$ 100$ million as an upfront investment and have $\$ 120$ million in return. Project II will cost 80 million as an upfront investment and have $\$ 60$ million in return. Project III will cost $\$ 60$ million as an upfront investment and have $\$ 40$ million in return. To calculate the probability index, using NPV divided by resource consumed. The results are as follows:

$$
\begin{aligned}
& \text { Profitability Index }=\frac{\text { value } \text { created }}{\text { Resource Consumed }}= \\
& \frac{N P V}{\text { Resource Consumed }}
\end{aligned}
$$

Table 2. Projects for a $\$ 100$ Million Budget

\begin{tabular}{llll}
\hline Project & NPV & $\begin{array}{l}\text { Initial } \\
\text { Investment }\end{array}$ & $\begin{array}{l}\text { Profitability } \\
\text { Index } \\
(\$ \text { millions })\end{array}$ \\
\hline I & 120 & 100 & NPV/Investment \\
\hline II & 80 & 60 & 1.2 \\
\hline III & 60 & 40 & 1.3 \\
\hline
\end{tabular}

Ranking these profitability Indexes and starting with the highest Index. The projects can be accepted until all the resources are used up.

To make the profitability index completely reliable, some conditions should be satisfied.

Jaffe and Randolph Westerfield [7] summarise that the resources should be completely consumed over the profitability index ranking. And the related resource constraint should be only one.

Although the profitability Index is practical, it still has some shortcomings. In most cases, the resource constraints that a firm meets could be variable and multiple. If that is the case, a simple index cannot be used to rank these projects, a more technical and advanced calculation will be developed to handle these problems.

\subsection{Venture Capitalists}

Venture Capitalists (VCs) is another way to evaluate 
high potential companies' projects. Tyebjee [8] was the first person to give a five stages VC process model, including deal origination, deal screening, deal evaluation, deal structuring and post-investment activities.

Sharma [9] explains that the deal origination is to measure a firm whether it is potential. The deal screening is to screen the proposals such as the technology, management, and the product. Deal evaluation evaluates the business plan, sees the projects' risk and return, and the deal structuring is to handle and set VC agreement. Finally, the post-investment activities are to provide value-added activities.

Most people agree with Monika's thoughts, who divided the criteria into six different categories. Macmillan et al.[10] show the categories: venture team, product attributes, market growth and size, expected return market growth and size, and management skill and experience. However, Meyer [11] finds that the VC process is an art since its inaccurate in self-introspection.

Kunkel and Hofer [12] state VCs verbal protocol analysis considers the criteria to be used and how much time is to be spent on the criteria. Hall [13] concludes that VCs verbal process is a better decision-making method than the post hoc method, concentrating on the results. In contrast, VCs verbal process can make a deep understanding in VCs decision-making process. Meyer [11] finds that VCs verbal process has its advantages like its collected data is reliable, but its disadvantage is that it is time-consuming.

VCs can be considered a quality method to evaluate the value of high potential companies 'projects. Before investing in projects, investors or managers can use the five stages and the six categories to analyse the company's performance and indirectly then assess whether the project has the potential.

\section{DISCUSSION}

In this section, we compared the different model's advantages and disadvantages.

NPV is a reliable and accurate way to determine whether the project is suitable to invest in or not while. IRR can give the same conclusions as the NPV rule if the project is standalone and its positive cash flows come after negative cash flows.

If the condition does not satisfy, the IRR rule will conclude a wrong investment decision. And the IRR rule will fall consequently. Although it has its shortcoming in evaluating a project, it is still valuable when combing the NPV rule, and it is helpful to indicate the sensitivity of the investment decision.

The payback method shows another thought to deal with the best investment decision. However, it is not a powerful tool as NPV and IRR rule. It ignored the time value of money and the cost of capital, and it does not consider the cash flows after the payback period. Profitability Index can be used to analyse the profitable projects and combine them within the budget, but it cannot play a good role when the resource constraints are complicated. Venture capitalists will be a good tool to evaluate the companies' projects while it also has the shortcomings of time-wasting. Since NPV is a more accurate method and VCs is more concentrated on the quality analysis, it is advised that NPV and VCs methods can be combined to satisfy the quantity and quality analysis.

\section{CONCLUSION}

In reality, not only corporate managers but also investors in different industries and firms are willing to invest. For managers, they may invest in an attractive project to maximize the shareholders' benefits to promote their performance. For investors, they may want to increase their wealth by investing in a good project. No matter which aims they want to achieve. They all have the incentive to search for a powerful investment method to help them evaluate the projects and tell them the correct decision. Therefore, this article introduces different investment decision-making methods and discusses how they apply the correct decision and the cons and pros of these methods.

To sum up, NPV is an accurate and practical rule for companies to decide, even though about one-fourth of the American companies do not use the method. IRR can conclude the same decision as to the NPV rule, but it only works when the project is stand-alone. The payback method can save time, but it neglects the time value of money and the cost of capital. The profitability index is efficient to make the optimal project combination while also having some conditions to satisfy. Venture Capitalists provides a better decision-making process while it is time-consuming.

The article finds out that even though multiple methods have been applied to evaluate the projects in the real world for many years, no methods are perfect. Thus, more research and studies in discovering a better rule that can be used in choosing the best project will be written in the future.

\section{REFERENCES}

[1] Griffith, S., \& Liyanage, L. (2008). An introduction to the potential of social networking sites in education.

[2] Berk, J., \& DeMarzo, P. (2011). Corporate Finance, global ed. Essex: Person Education Limited.

[3] Brealey, R. A., Myers, S. C., Allen, F., \& Mohanty, P. 
(2018). Principles of Corporate Finance, 12/e (Vol.

12). McGraw-Hill Education.

[4] Allen, F., Brealey, R., \& Myers, S. (2006). Corporate finance. Auflage, Boston (ua): McGraw-Hill Irwin.

[5] Tirole, J. (2010). The theory of corporate finance. Princeton University Press.

[6] Silber, W. L. (2008). NPV Versus IRR.

[7] Jaffe, J., \& Randolph Westerfield, R. (2004). Corporate finance. Tata McGraw-Hill Education.

[8] Tyebjee, T. T., \& Bruno, A. V. (1984). A model of venture capitalist investment activity. Management science, 30(9), 1051-1066.

[9]Sharma, A. K. (2015). Venture Capitalists' Investment decision criteria for new ventures: A Review. Procedia-Social and Behavioral Sciences, 189, 465-470.

[10] MacMillan, I. C., Siegel, R., \& Narasimha, P. N. (1986). Criteria used by venture capitalists to evaluate new venture proposals. Journal of Business venturing, 1(1), 119-128

[11] Zacharakis, A. L., \& Meyer, G. D. (1995). The venture capitalist decision: understanding process versus outcome. Frontiers of entrepreneurship research, 1995, 465-78

[12] Kunkel, S., \& Hofer, C. W. (1990, August). Why study the determinants of new venture performance: A literature review and rationale. In Academy of Management Proceedings.

[13] Hall, J., \& Hofer, C. W. (1993). Venture capitalists' decision criteria in new venture evaluation. Journal of Business Venturing, 8(1), 25-42 